\title{
Disaster vulnerability, displacement, and infectious disease: Nicaragua and Hurricane Mitch
}

\section{Peter Loebach ${ }^{1}$ (D) $\cdot$ Kim Korinek ${ }^{2}$}

Published online: 25 April 2019

(C) Springer Nature B.V. 2019

\begin{abstract}
Research conducted among socially vulnerable populations caught in the paths of natural disasters represents the forefront of our understanding the health-related impacts of climate change. In this study, we analyze individual-level longitudinal data from the Nicaragua Living Standards and Measurement Survey $(N=3474)$ in order to ascertain the influence of disaster displacement arising from the Hurricane Mitch event upon two communicable disease outcomes: diarrheal disease and respiratory disease. First, multinomial logistic regression analyses demonstrate that individuals from households headed by women, as well as from households with low levels of consumption expenditures, experienced greater odds of displacement to shelters in the aftermath of Mitch. Second, two-way fixed-effects regression analysis demonstrates that shelter displacement acts as independent risk increasing the odds of respiratory disease, net of socioeconomic and demographic covariates. Our findings draw attention to the confluence of far-reaching entrenched social and economic disparities that create linked disaster displacement and communicable disease vulnerabilities.
\end{abstract}

Keywords Disaster $\cdot$ Natural hazard $\cdot$ Infectious disease $\cdot$ Displacement $\cdot$ Respiratory disease $\cdot$ Migration

Peter Loebach

pjloebach@ecsu.edu

Kim Korinek

kim.korinek@soc.utah.edu

1 Social and Behavioral Sciences Department, Elizabeth City State University, 1704 Weeksville Road, Campus Box 851, Elizabeth City, NC 27909, USA

2 Department of Sociology, University of Utah, 380 S 1530 E RM 301, Salt Lake City, UT 84112, USA 


\section{Introduction}

As a direct result of anthropogenic climate change, extreme weather events such as heat waves, droughts, hurricanes, and cyclones will increase in frequency and severity in the future (IPCC 2013). Research conducted among populations caught in the paths of disasters provides mounting evidence that broad-scale, systemic changes in climate are significantly altering the global burden of disease (Campbell-Lendrum and Woodruff 2006; Patz et al. 2005). Because globally scaled environmental hazards confer the greatest health burdens upon the world's poor - those least culpable for carbon emissions and global temperature rise-Patz and colleagues (2007:1) conceptualize climatechange linked disease morbidities as possibly "the largest health inequity of our time." Climate disaster events and their associated communicable and non-communicable disease impacts also disproportionately befall communities already facing heavy disease burdens due to their precarious positions in global socioeconomic systems. Recognizing that climate change induces further risk and precarity for the world's poor, compounding extant global social, economic, and epidemiological disparities, our aim in this paper is to interrogate the ways that disaster event exposure, and subsequent displacement, combine with socially structured risk factors to yield unique disease impacts. We focus our investigation upon Nicaragua, a middle-income country that, like many others in the Global South, faces high risks of future climate-linked disaster events.

Beyond altering climatic conditions which expose larger populations to stressors such as extreme heat (and heat stroke risk) and expanding geographic distributions of vector organisms (such as those carrying malaria and dengue), climate change introduces extensive, complex non-climatic shifts with potentially grave consequences for health (Campbell-Lendrum and Woodruff 2006; McMichael 2003). Compelled migration is one such shift and is chief among the secondary stressors met by disasterexposed populations (Fussell and Lowe 2014). Those displaced from dwellings or livelihoods may move toward areas with heightened risk of water- or air-borne disease transmission, or other risks, such as flooding. Migratory displacement to temporary shelters, a common adaptation in the face of natural disaster, may move populations away from disaster sites, but into contexts that heighten the risk of sustaining injury, contracting communicable disease or succumbing to adverse mental health outcomes. Accordingly, to manage and avert the worst possible epidemiological consequences of climate change, it is urgent to understand how preexisting socially determined health disparities interact with modes of exposure and adaptation to extreme climate events to shape post-disaster disease morbidity patterns and risk factors.

Our study investigates vulnerability to negative health outcomes in the aftermath of a natural disaster and focuses on displacement as a critical pathway in this association. To this end, we utilize longitudinal data from Nicaragua, collected prior and subsequent to Hurricane Mitch, in order to analyze post-disaster displacement as a mechanism through which climate events influence health outcomes. We build upon recent theoretical and empirical work that grapples with social inequality as a cause and outcome of environmental migration (e.g., McLeman et al. 2016:11) and highlights the interaction between environmental, social, and socioeconomic processes. Our examination takes this logic a step further by considering the implications for epidemiological contexts and health disparities. We conceive of migration, specifically involuntary 
displacement to a temporary shelter, as a condition that affects relatively socially vulnerable populations and acts as a mechanism through which exposure to climate disaster events heightens the risk of additional vulnerability in the form of communicable disease susceptibility. Our analyses advance an understanding of disaster-induced disease risks as encompassing disaster-related experiences, specifically displacement to shelters, as well as ongoing structural factors that harm health including weak institutions, poverty, and social marginalization.

\section{Literature review: vulnerability, health, and processes of displacement}

The conceptual framework for our analyses draws upon recent efforts to unite disaster vulnerability and population health scholarship, while also integrating insights from the environmental migration literature. Population health perspectives root health status in social context, conceiving of disease risk as stemming from social experiences at individual, community, national, and international levels. The result is a view of disease as fundamentally social in nature, its determinants emerging from multiple layers of causality, including the proximal and distal, the environmental and social structural, each intersecting to influence specific disease risks (Ezzati et al. 2002; Lopez et al. 2006; Marmot 2005). Related ecological approaches understand health disparities as arising from vulnerable populations' geographic segregation in areas with poor infrastructure and public services and heightened exposure to stressors and pollution (Gee and Payne-Sturges 2004).

Alongside and compounding extant socioeconomic disparities in health status and access to healthcare, social and geographic factors make poor populations particularly exposed to natural hazards and ill equipped to positively adapt to their consequences. The interdisciplinary, vulnerability science approach to natural disasters draws connections between extant social disparities and individual characteristics influencing risk of exposure and ability to recover from a natural event (Cutter and Emrich 2006; Finch et al. 2010; Blaikie et al. 2014). The vulnerability perspective maintains that the nature and severity of disaster impacts are a function of features of the hazard event, including its magnitude and its form (e.g., earthquake or hurricane), along with the characteristics of communities and groups experiencing exposure to a hazard (Blaikie et al. 2014; Cutter et al. 2003; Tierney 2006). By locating their impacts in "social conditions more than nature," the vulnerability approach "denaturalizes" disasters (Adams et al. 2011:1; Klinenberg 1999).

Recent works bridge the disaster vulnerability and social determinants of health literatures, recognizing that the factors associated with the social determinants of health "are the same as those commonly associated with disaster vulnerability" (Lindsay 291:Lindsay 2003). As Few and Tran (2010:530) note, the population health and disaster vulnerability frameworks share common notions of multiple resources and complex capabilities influencing risk. At the macro/distal level, natural and technological disasters precipitate a confluence of physical and psychosocial stressors (Ginexi et al. 2000; Kaniasty and Norris 2000) which layer upon extant health risks emanating from the disadvantageous neighborhoods and built environments within which the world's poor disproportionately reside (Ross and Mirowsky 2001; Gordon-Larsen et al. 2006). Communities within developing countries, strained to provide access to 
sanitation and clean water even during times of stability, are prone to a combination of vulnerabilities which heighten the risk of disaster exposure and post-disaster disease impacts (Leaning and Guha-Sapir 2013; Toole 1997). At the same time, at the micro/ proximal level, social disadvantage relates to a host of factors with implications for health in the context of disasters (Few 2007). Some factors, such as access to health care, nutrition, and protective behaviors, are directly connected to health. Others, including income, livelihood, physical location, education, and social support networks, are related to capabilities to avoid detrimental experiences associated with disasters that have cascading effects upon health (Few 2007; Few and Tran 2010; Klinenberg 1999).

\section{Disaster displacement and health}

Post-disaster displacement may trigger a host of negative experiences which mediate disaster events' associations with negative physical and mental health outcomes, including loss of income, disruption of social support systems, domestic violence, and severed connections with natural resources, social welfare, and health care (Hori and Schafer 2010; Morris et al. 2002; Wolsko and Marino 2016). The World Health Organization finds displacement to be the primary risk factor influencing susceptibility to communicable diseases in the context of natural disaster events (Ezzati et al. 2002; Watson et al. 2007). Displacement is at the root of post-disaster communicable disease transmission, in part because displaced persons encounter crowding, poor ventilation, underprovisioned privies, and compromised water supplies in shelters - a combination of conditions that encourage communicable disease transmission (PAHO 2000; Noji 2005; Watson et al. 2007). Such conditions, met by populations with heightened susceptibility to disease onset, such as those suffering from physical and psychological trauma, and malnourishment due to food shortage, can result in the reduction of already low levels of disease immunity (Toole 1997).

The prominent role of displacement in the etiology of post-disaster disease transmission demands that we attend to processes of displacement and the populations prone to displacement to temporary and emergency shelters (Quarantelli 1982; McMichael 2013; Toole 2005). Scholarly evidence demonstrates that rather than a singular, undifferentiated experience, disaster displacement is multidimensional. The duration, distances and conditions of displacement, and the likelihood of return vary widely in ways that coincide with pre-disaster class, racial-ethnic, and other social disparities (Fussell and Lowe 2014). Environmental shocks interact with migration processes to generate an array of movements, some of which demonstrate an unforeseeability, vulnerability, and lack of agency characteristic of refugee movements, others of which demonstrate strategizing and mobilization of material and social resources more characteristic of economic migration (Hugo 1996; Loebach 2016; McMichael 2013). The conditions, timing, and outcomes of migration in the face of a disaster event are widely disparate, encapsulating differential access to a host of resources. Evacuation may be an ideal adaptive response to a foreseen hazard, but economic constraints can place limitations on being able to depart from a livelihood, access evacuation transportation, reside with family elsewhere, or locate an emergency shelter (Quarantelli 1982). In New Orleans, for example, failures to evacuate in the face of Hurricane Katrina, or illtimed evacuations, often resulted from a lack of social and economic resources and 
severely inadequate government emergency services, such as for evacuating elderly and institutionalized populations (Adams et al. 2011).

In a seminal study of vulnerability to disasters and human mobility in the US context, Morrow-Jones and Morrow-Jones (1991) find that poverty, female household headship, elderly age, racial/ethnic minority status, and low levels of education correlate with post-disaster migration. Lower socioeconomic status households are more likely to reside in dwellings positioned in the "firing line" of natural hazards (Paavola 2008) and in fragile, unstable dwellings with low-quality construction and minimal disaster mitigation features (Fothergill and Peek 2004; Myers et al. 2008). Displacement from the primary dwelling does not necessarily imply movement to a temporary or emergency shelter. One estimate finds that large-scale public shelters, considered the site of last resort, house less than one-quarter of populations seeking post-disaster shelter (Bolin and Stanford 1990; Peacock et al. 2007). Other frequent sites of interim shelter are hotels and the homes of others within one's social network (Fussell and Lowe 2014). However, financial capital and time taken off from work may be required for the former, while strong social capital may be a pre-requisite for the latter.

Empirical studies examining risk factors for displacement to disaster evacuation centers are limited (Gray et al. 2014; Levine 2007; McLeman and Hunter 2010; Peacock et al. 2007). However, research in this vein reveals patterns that mirror historical accounts linking gender, poverty, old age, landlessness, and other forms of vulnerability to the negative consequences of natural disasters (McLeman et al. 2016). In a focused examination of displacements to public evacuation centers, Greenough et al. (2008) find that survivors of Hurricane Katrina displaced to Red Cross shelters in New Orleans were more likely to be racial minorities, women, members of femaleheaded households, renters, and un- or underinsured. Brodie et al. (2006) observe a similar profile of Hurricane Katrina evacuees in displacement shelters in Houston. In developing country contexts, Rofi et al. (2005) find that movements to displacement camps induced by the Indian Ocean tsunami in Aceh were more likely to be made by male-headed households, while female-headed households were more likely to find refuge in homes. A subsequent study of displacement in Sumatra after the Indian Ocean Tsunami conducted by Gray et al. (2014) finds the opposite to be true of female-headed households: they were more likely than male-headed households to experience displacement to a camp. They also find low levels of education to be associated with experiencing displacement to a camp. Mallick and Vogt (2014), examining the impacts of a cyclone event in Bangladesh, found that persons displaced to urban slum areas tended to have relatively low levels of income and capital ownership.

\section{Note on analytical approaches in disaster and health research}

Several climate change and health scholars lament a relative paucity of investigations on the "indirect pathways that link climate change to resultant social, economic and demographic disruptions and their knock-on health effects" (McMichael et al. 2006:860). The intersection of extreme climate events and displacement provides one unique angle for delineating a key mechanism through which climate change yields health impacts. Few scholars have wielded the data and analytical tools necessary to establish the causal pathway between disaster exposure, displacement and health. Uscher-Pines" (Uscher-Pines 2009:1) meta- 
analysis of disaster displacement's influence on health outcomes notes that, "the few examples in the literature reveal weak study designs, inconsistent results, and inattention to physical health impacts and the challenges facing vulnerable populations." Additionally, few studies to date assess household-level risk factors in low-middle income, risk-prone country contexts. This paper addresses this lacuna, asking: Is displacement to a shelter from a natural disaster associated with increased risk of the communicable diseases of respiratory or diarrheal disease? And, what social characteristics are associated with the risk of experiencing displacement to a shelter? By addressing these questions using pre- and postdisaster longitudinal data, with methods that jointly analyze individual and household level factors shaping vulnerability to displacement and ill health, we contribute a novel perspective on the specific, influential mechanism of displacement upon post-disaster population health risks.

\section{Hurricane Mitch and the Nicaraguan context}

Estimated by the National Oceanic and Atmospheric Association to be the most destructive hurricane to hit the western hemisphere since The Great Hurricane of 1780 (NOAA 2009), Hurricane Mitch delivered extreme rainfall to countries across the Central American region in December 1998. The storm broached Nicaragua from its northern border with Honduras, inundating Nicaragua's North and Northwest regions with severe wind and rain (ECLAC 1999; USAID 1999). Although impacts concentrated in the northern regions nearest to the storm center, record rainfall and associated devastation occurred in areas even hundreds of miles from the hurricane eye. Whole communities proximate to the Casita Volcano were buried when the volcano cone flooded and collapsed, and riverine communities across the country experienced devastating flooding and landslides. In addition to approximately 3000 persons killed (Steele 2001), Hurricane Mitch rendered hundreds of thousands homeless and visited extensive damage upon infrastructure, including roads, bridges, power lines, sewage systems, and health care facilities (Cupples 2004). Infrastructure damage, totaling over $\$ 349$ million according to one estimate (McHugh 1999), included the overflooding of hundreds of latrines, a situation that led the Ministry of Health to declare an epidemic emergency (Cupples 2007). At the same time, the hurricane wrought an estimated \$239 million in damages to the social sectors, including public health systems for the containment of epidemics (ECLAC 1999; McHugh 1999; PAHO 2000).

To date, research on Hurricane Mitch's health impacts has focused largely at the individual level. Baez and Santos (2007) find that children in municipalities heavily impacted by Mitch were more likely to be undernourished and less likely to have received health care treatment (Baez and Santos 2007). Goenjian et al. (2011) find high levels of post-traumatic stress and depressive symptoms among adolescents who encountered traumatic experiences as a result of the event. One narrowly focused epidemiological study does observe a fourfold increase in rates of acute respiratory disease in one Mitch-impacted municipality (Campanella 1999). Yet, in terms of differential vulnerability, we know of no studies to date on the social distribution of health impacts related to Hurricane Mitch in Nicaragua. 
Research on population movements in the context of Hurricane Mitch finds that certain types of migrations in the years surrounding the event were associated not with social disadvantage, but rather with capability for adaptation in the face of a shock. Carvajal and Pereira (2009) find hurricane exposure encouraged migration among those with intermediate levels of wealth and discouraged migration among the poor. Loebach (2016) similarly finds that following the hurricane, migration streams became more highly selective of those with access to migrant networks.

While estimates of the number of Nicaraguan residents who evacuated at the time of the hurricane vary substantially, all place the total in the hundreds of thousands (e.g., 300,000 (USAID 1999), 800,000 (NOAA 2009)). Most persons who evacuated were absent from their homes for only a brief period, only until the storm waters subsided and the initial emergency phase was over. Those who would continue to reside in temporary shelters for over a month numbered approximately 65,000 , a number that would continue to decrease in the following months (ECLAC 1999; USAID 1999). By March 1999, roughly 4 months after the rains subsided, almost all evacuees had left displacement shelters. Some moved into permanent resettlement areas, some moved in with family members, and some returned to their homes and land (USAID 1999). Common shelter sites were schools, churches, and tent communities set up by NGOs. On conditions of the temporary shelters, the United Nations (ECLAC 1999) reports a host of inadequacies including a lack of psychological and social rehabilitation services, non-integration of community organizations into shelter operations, insufficient care for children, and "major sanitation problem[s]"( 1999:14). Critically, although several studies on migration in the context of Hurricane Mitch assess the selectivity of migration streams (e.g., Carvajal and Pereira 2009; Loebach 2016), these studies do not include displacement. By analyzing the social characteristics associated with displacement to shelters and with infectious disease morbidities, we aim to shed new light upon a form of post-disaster migration that is central in pathways connecting climate change, disasters, and health.

\section{Hypotheses}

Using longitudinal household-level data from Nicaragua, we examine household characteristics associated with experiencing displacement to a shelter as a result of Hurricane Mitch and the subsequent influence of displacement on individual health outcomes. Specifically, we hypothesize that the following markers of ongoing social vulnerability influence the odds of becoming displaced to a shelter: low levels of household expenditures, being a home renter (as opposed to homeowner), low levels of education, and female household headship. We expect that these markers of social vulnerability will not be similarly associated with displacement to other types of interim housing, due to resources and social standing providing means of avoiding shelter displacement. We also hypothesize that displacement to a shelter will be associated with increased likelihood of contracting communicable diseases, in particular respiratory and gastrointestinal diseases. Again, we do not expect that displacement to other types of interim housing will have significant effects on communicable disease outcomes. 


\section{Data and method}

To conduct our analyses, we utilize data drawn from the Nicaragua Living Standards and Measurement Survey (LSMS), collected by the Nicaraguan National Institute for Statistics and Censuses (INEC) with the support of the World Bank. Administered in more than 20 countries globally, LSMS surveys are household-level surveys, administered to household heads, which pose extensive questions pertaining to the condition of entire households as well as individual members.

A wave of the Nicaragua LSMS was conducted between May and August of 1998, at which time 4040 households and 23,643 individuals were surveyed (Steele 2001). Hurricane Mitch struck later that year, in late October. Officials at INEC took advantage of the opportunity to build a panel dataset spanning the Hurricane Mitch event and containing information related to the Hurricane's impacts by organizing a post-Mitch data collection wave carried out in May and June of 1999. There were two criteria for inclusion of households in the 1999 collection wave. Households must have been surveyed in the 1998 data collection wave, and they must have been in municipalities designated by INEC as "heavily affected" by the hurricane (Steele 2001; World Bank 1998). Figure 1 displays the designated municipalities. The majority are located in the northwestern area of the country, the region that experienced the storm's highest rainfall intensity (Davis 2017). They also include select municipalities in the central and eastern region of the country, including Waspan, Paiwas, and La Cruz de Rio Grande - all largely riverine municipalities that were subject to severe flooding from the country's major rivers, the Coco River and the Rio Grande de Matagalpa (Steele 2001). In the event that the home dwelling was destroyed, INEC made effort to locate the household within the municipality. We do not know if, or to what extent, households were not able to be located, an acknowledged study limitation. In addition, INEC notes that including only households previously visited in 1998 means the "[1999] data cannot be used as representative of the areas affected by Hurricane Mitch" (Steele 2001:2). While these panel data have their limitations, they provide rare insights into a range of pre- and post-disaster household conditions, such as livelihoods, and loss and recovery of assets (Loebach 2019; Van den Berg 2010; Premand and Vakis 2010); and behaviors, such as fertility, migration, and consumption (e.g., Davis 2017; Loebach 2015; Jakobsen 2012; Carvajal and Pereira 2009).

We calculate descriptive statistics and $t$ tests to compare the post-disaster sample with the nationally representative sample prior to the hurricane, at $t=1998$. Table 1 presents results. Two-tailed $t$ tests find the heavily affected are distinguishable from the nationally representative sample in terms of rates of dwelling ownership, levels of consumption, levels of education, sex composition, household size, rural status, and rates of respiratory disease. Consistent with other accounts (e.g., Villacis 2004), the results find an association between social vulnerability characteristics and experiencing impacts from the hurricane, as those designated as heavily affected were, prior to the hurricane, of lower socio-economic position and with higher rates of rural residence. They also feature lower rates of respiratory disease symptoms, likely due to their comparatively low rates of residence in urban areas conducive to respiratory disease (Sakisaka et al. 2006).

\footnotetext{
${ }^{1}$ INEC does not provide detail on the methodology used to distinguish "heavily affected" municipalities.
} 


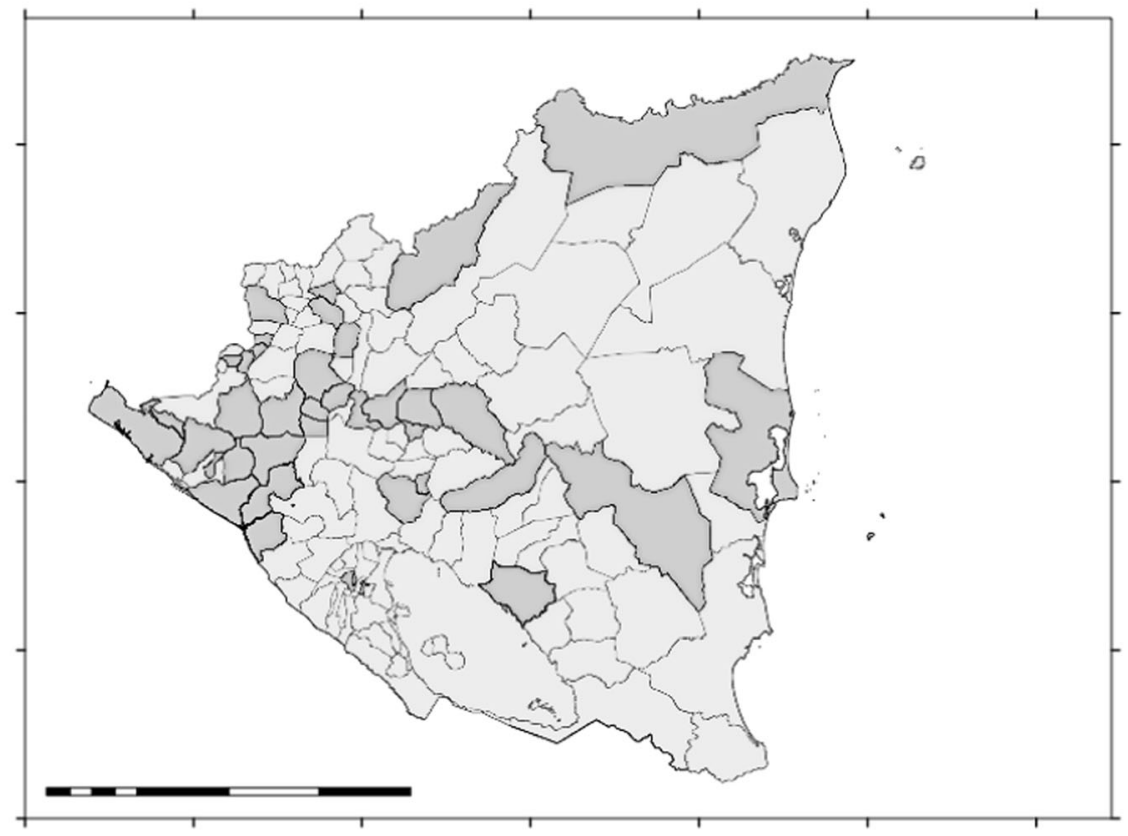

Fig. 1 Municipalities of households selected by INEC for inclusion in 1999 data collection wave (indicated in dark)

Table 1 Sample characteristics for nationally representative sample and those designated as "heavily affected," $t=1998$

\begin{tabular}{llll}
\hline Variable description & $\begin{array}{l}\text { Total } \\
\text { sample at } t=1998\end{array}$ & $\begin{array}{l}\text { "Heavily } \\
\text { affected" at } t=1998\end{array}$ & $\operatorname{Pr}(|T|>|t|)$ \\
\hline$N$ & 23,643 & 3474 & - \\
$\begin{array}{l}\text { Demographic characteristics } \\
\text { Age }\end{array}$ & 22.55 & 22.42 & 0.8369 \\
Sex: female (\%) & 50.96 & 49.21 & 0.0359 \\
HH size (mean) & 5.55 & 5.81 & 0.0216 \\
$\begin{array}{l}\text { Socioeconomic characteristics } \\
\text { Household head education: } \\
\text { high school and higher (\%) }\end{array}$ & 16.28 & & 0.0000 \\
$\quad$ Rural community (\%) & 45.87 & 10.22 & 0.0000 \\
$\quad \begin{array}{l}\text { Dwelling ownership: own dwelling (\%) } \\
\text { Consumption (mean cordobas/cap) }\end{array}$ & 77.69 & 72.92 & 0.0048 \\
Communicable disease prevalence & 6890 & 72.91 & 0.0000 \\
$\quad$ Diarrheal disease, prevalence(\%) & 0.71 & 4736 & 0.2847 \\
$\quad$ Respiratory disease, prevalence & 24.23 & & 0.0009 \\
$\quad$ Measles, prevalence & 1.16 & 21.79 & 0.2330 \\
\hline
\end{tabular}

$\dagger p<0.10 ; * p<0.05 ; * * p<0.01 ; * * * p<0.00$ 
The 1999 survey inquires whether households were subject to certain experiences, including displacement, as a direct result of the hurricane. One question inquires, Was the home dwelling temporarily uninhabited as a result of Hurricane Mitch? A follow-up question probes, During this time, the household moved to (a) a shelter [refugio], (b) home of family/friend, c) an improvised dwelling, (d) another municipality, (e) another department, (e) another country. Table 2 presents descriptive statistics on prevalence of these experiences in the sample. We designate as displaced to a shelter those persons belonging to households that provided affirmative responses to answer (a) movement to a shelter [refugio]. Three hundred twenty-two persons within the sample were designated as moving to a shelter, out of a total of 3474. We also designate persons having experienced all other categories of movement, as indicated by responses (b), (c), (d), or (e) to the probe question. Six hundred thirty-four persons reported having experienced these other movements. By the time the survey was conducted, no respondents remained displaced.

A question posed at the individual-level asks, In the last month, did [this individual] have any of the following diseases: cough or respiratory problem; measles; traumatic accident; diarrhea; or other disease. Responses to this question form the basis of the outcome variables of respiratory disease and gastrointestinal distress, two communicable disease outcomes linked to disaster displacement shelters. ${ }^{2}$ Overwhelmed shelters may experience food and water contamination, which facilitates the spread of respiratory pathogens (Bellos et al. 2010). Other risk factors for acute respiratory disease associated with displacement conditions include poor ventilation and exposure to cold temperatures (Bellos et al. 2010; Watson et al. 2007). Diarrheal diseases also flourish in post-disaster contexts and contribute to post-disaster morbidity and mortality outcomes (Leaning and Guha-Sapir 2013; Toole 1997; Waring and Brown 2005). Table 3 presents descriptive statistics of the prevalence of these health outcomes, stratified according to having experienced displacement to a shelter or to other types of interim housing.

\section{Modeling displacement outcomes}

In our first estimation, we use multinomial logistic regression model likelihood of being displaced from the home dwelling to (a) a shelter and (b) any of the other type of interim housing (i.e., the home of family/friends, an improvised dwelling, another department, another municipality, or another country). We include as predictive variables characteristics found in past research to be associated with vulnerability to disaster impacts. These include level of household consumption, level of education, female household headship, dwelling ownership, employment in the nonagricultural sector, household size, and social participation (Gray et al. 2014; Blaikie et al. 2014). The household consumption measure consists of an aggregate of per-capita food and non-food item expenditures. ${ }^{3}$ We categorize levels of consumption according to

\footnotetext{
${ }^{2}$ The low prevalence of measles in the sample prohibits multivariate modeling of this health outcome.

${ }^{3}$ Price variation in consumption costs across geographic areas are accounted for through use of an adjustment according to a price quotation calculated at the level the municipality (ECLAC 1999).
} 
Table 2 Displacement variables $(t=1999)$

\begin{tabular}{lll}
\hline Displacement variables & Number & $(\% N)$ \\
\hline Displaced to a shelter & 322 & 9.27 \\
Displaced to an improvised dwelling & 106 & 3.05 \\
Displaced to home of family/friend & 491 & 14.13 \\
Displaced to municipality & 11 & 0.31 \\
Displaced to another department & 6 & 0.17 \\
Displaced to another country & 19 & 0.55 \\
\hline
\end{tabular}

quintiles, represented by four binary variables, with the highest quintile households designated as the reference category. We operationalize household human capital through a measure of the highest level of education attained by the household head or the head's spouse, dichotomized to indicate whether she/he attended high school or tertiary education. Female headship is included as a predictive variable related to vulnerability, given its association with poverty and employment problems in the Nicaraguan context. Individuals experiencing social isolation and weak bonds of social capital (Coleman 1988) are often less capable of adaptation in the face of shocks (Klinenberg 1999; Pelling and High 2005; Cutter et al. 2003). For displacement in particular, social networks may provide access to alternative temporary shelter aside

Table 3 Descriptive statistics

\begin{tabular}{|c|c|c|c|}
\hline Variable description & Total $(\% N)$ & $\begin{array}{l}\text { Displaced } \\
\text { to shelter }(\% N)\end{array}$ & $\begin{array}{l}\text { Displaced to other } \\
\text { types of interim } \\
\text { housing }(\% N)\end{array}$ \\
\hline$N$ & 3474 & $322(11.17)$ & $634(18.25)$ \\
\hline \multicolumn{4}{|l|}{ Health } \\
\hline Diarrheal disease, year 1999 & $101(2.91)$ & $15(5.32)$ & $20(3.23)$ \\
\hline Respiratory disease, year 1999 & $719(20.70)$ & $72(23.84)$ & $100(16.18)$ \\
\hline Measles, year 1999 & $57(1.64)$ & $1(0.31)$ & $3(0.49)$ \\
\hline \multicolumn{4}{|l|}{ Control variables } \\
\hline Sex of household head: female $(\%)$ & 18.15 & 21.52 & 9.58 \\
\hline HH education: high school \& higher (\%) & 44.50 & 44.37 & 57.14 \\
\hline Rural community (\%) & 75.39 & 65.89 & 83.87 \\
\hline Active in community organizations $(\%)$ & 26.17 & 33.44 & 30.08 \\
\hline Dwelling ownership: own dwelling (\%) & 73.75 & 65.56 & 78.49 \\
\hline HH size (mean) & 8.14 & 8.39 & 8.89 \\
\hline HH member participate in non-agricultural sector & 55.21 & 57.62 & 51.60 \\
\hline Consumption quintile 1 (mean cordobas/cap) & 1626 & 1523 & 1606 \\
\hline Consumption quintile 2 (mean cordobas/cap) & 2987 & 3064 & 2960 \\
\hline Consumption quintile 3 (mean cordobas/cap) & 4360 & 4470 & 4280 \\
\hline Consumption quintile 4 (mean cordobas/cap) & 6372 & 6444 & 5936 \\
\hline Consumption quintile 5 (mean cordobas/cap) & 12,687 & 13,458 & 11,544 \\
\hline
\end{tabular}


from a displacement camp (Elliott et al. 2010; Gray et al. 2014). For these reasons, we include a measure of social network connection, coded " 1 " if a member of the household participates regularly in some type of community organization (i.e., development, school, sports, religious, professional organization), and " 0 " if not. To account for the geographic location of households, we utilize a binary categorical variable, coding those households residing in rural communities prior to the hurricane as 1 and those in urban areas as 0 . We account for geographical variance in the hurricane's impacts through fixed effects employed at the departamento level. Also, because individuals are embedded in households, and households are embedded in regions, the data are likely grouped into clusters. We therefore employ bootstrapped standard errors to account for potentially clustered errors (Cameron et al. 2008).

\section{Modeling disease outcomes}

The second set of analyses estimate the likelihood of experiencing the health outcomes of diarrheal disease and respiratory distress. Including displacement as a predictor alongside variables representing socio-economic status in models predicting health outcomes introduces the potential for biased estimation. A priori, an individual might be selected into displacement based on household socio-economic characteristics that are themselves directly related to health outcomes. The longitudinal design of the Nicaragua LSMS permits inclusion of person-specific fixed effects to minimize bias in estimators that may arise due to endogeneity. Person-specific fixed effects absorb differences between individuals who experienced displacement, and those that did not that are fixed over time. They also control for other causes of unobservable heterogeneity at the person level that are time-invariant. In addition, we control for the effect of time through inclusion of a period-specific time point variable, as time, if correlated with the displacement variable, may contribute to biased estimates. Thus, we estimate two-way fixed-effects models according to the following regression formula:

$$
Y_{i t}=\alpha_{1} T_{t}+\alpha_{2} A_{t i}+u_{i}+e_{i t}
$$

According to this specification, $T$ is a year specific dummy employed for the year 1999; $A$ denotes a dummy designating experiencing displacement, with the treatment effect identified by the parameter $\alpha_{2}$; and $u$ is a person-specific fixed effect. The two-way fixed effects model assumes a common treatment effect, $\alpha_{2}$, and a common trend, $\alpha_{1}$, across treatment and non-treatment groups (Chaisemartin and Haultfoeuille 2018). Additional assumptions necessary for drawing causal inference according to this specification include that past treatment has no influence on the outcome and that past outcomes do not hold influence on the current treatment (Imai and Song 2012). We argue that the former assumption is met on the grounds that the Hurricane Mitch event was a "treatment" without precedent. As to the latter assumption, we argue that it is unlikely that disease symptoms would bring about some form of displacement, but we do acknowledge that disease symptoms might influence displaced individuals' choice of where to go if able to choose from multiple options. We acknowledge this study limitation. The usage of variables at multiple scales implies potential clustering of standard errors; we therefore employ bootstrapped standard errors as a corrective for 
potential clustering of individuals within households and households within municipalities (Cameron et al. 2008).

In addition to presenting the results of model estimations in terms of odds ratios and $p$ values (provided in Tables 4 and 5), to facilitate practical interpretation for a policy audience, we discuss our results in terms of the average marginal effect (AME), the marginal effect of predictors on the conditional mean when other covariates are held at their observed values (Cameron and Trivedi 2010; Williams 2012).

\section{Results}

\section{Models predicting displacement to shelters and other types of interim housing}

Table 4 presents the results of multinomial logistic regression estimating the likelihood of displacement to (a) a shelter and (b) other types of interim housing. Consistent with our hypothesis, specific socioeconomic characteristics that are a priori linked to social vulnerability show statistically significant associations with displacement to a shelter $(p<0.05)$. In comparison with those in the highest consumption category (predicted probability $=5.54 \%$ ), probability of displacement to a shelter is $3.87 \%$ higher for those in the lowest consumption category, $4.93 \%$ higher for those in the second quintile, and $5.11 \%$ higher for those in the middle quintile. Also consistent with our hypotheses, we find statistically significant associations between shelter displacement and variables representing education, dwelling ownership, and female household headship. Households in which the head or spouse of head have a relatively high level of education demonstrate a $2.23 \%$ decrease in the probability of experiencing displacement to a shelter (ref: low education, predicted probability $=9.84 \%$ ). Being from a female-headed household is associated with a $3.23 \%$ increase in the probability of becoming displaced to a shelter (ref: male-headed household, predicted probability $=8.15 \%$ ). Contrary to our hypothesis that resources provide alternatives to becoming displaced a shelter, our estimation finds being from a household in which a household member participates in a community organization is associated with a $4.38 \%$ increase in the probability of experiencing displacement to a shelter (ref: non-participation, predicted probability = $7.61 \%$ ).

Inconsistent with our hypothesis that markers of social vulnerability would associate with displacement to a shelter, but not displacement to other types of interim housing, there are certain parallel associations across these outcome categories. Similar to displacement to a shelter, the two lowest consumption categories are associated with heightened likelihood of experiencing displacement to other types of interim housing. Compared to those in the highest consumption category (predicted probability = $10.48 \%$ ), probability of displacement to other types of interim housing is $9.23 \%$ higher for those in the lowest category and $8.88 \%$ for those in the second lowest category. However, while the third consumption category is associated with increased probability of experiencing displacement to a shelter, we find no such association with displacement to other types of interim housing. Rural status is associated with a $6.86 \%$ increased probability of experiencing to displacement to other types of interim housing (ref: urban status, predicted probability $=11.05 \%$ ). Furthermore, results find positive relationships with other socio-economic predictors, results that are consistent with our 
Table 4 Multinomial logistic regression predicting displacement

\begin{tabular}{|c|c|c|c|c|}
\hline & \multicolumn{2}{|c|}{ Shelter displacement } & \multicolumn{2}{|c|}{$\begin{array}{l}\text { Displacements to other } \\
\text { types of interim housing }\end{array}$} \\
\hline & RRR & $P>t$ & RRR & $\mathrm{P}>\mathrm{t}$ \\
\hline Consumption quintile: one & $2.09 * *$ & 0.001 & $2.35 * *$ & 0.001 \\
\hline Consumption quintile: two & $2.37 * * *$ & 0.000 & $2.31 * *$ & 0.004 \\
\hline Consumption quintile: three & $2.13 * *$ & 0.002 & 0.86 & 0.640 \\
\hline Consumption quintile: four & 0.76 & 0.393 & 1.21 & 0.509 \\
\hline Sex of household head: female (ref: male) & $1.31 *$ & 0.033 & $0.32 * * *$ & 0.000 \\
\hline $\begin{array}{l}\text { HH Education: high school \& higher } \\
\text { (ref: below HS) }\end{array}$ & $0.73 \dagger$ & 0.055 & 0.96 & 0.648 \\
\hline Rural community & 0.82 & 0.159 & $1.80 * *$ & 0.001 \\
\hline Dwelling ownership & 0.85 & 0.321 & $1.31 *$ & 0.033 \\
\hline Active in community organizations & $1.76^{* * *}$ & 0.000 & 1.03 & 0.791 \\
\hline Household size & 1.02 & 0.281 & 1.01 & 0.570 \\
\hline $\begin{array}{l}\text { Economic sector, participation in } \\
\text { non-agricultural sector }\end{array}$ & 0.77 & 0.171 & $1.41 * *$ & 0.009 \\
\hline Intercept & $4.53 \mathrm{e}-09 * * *$ & 0.000 & $3.14 \mathrm{e}-09 * * *$ & 0.000 \\
\hline$N$ & 3474 & & & \\
\hline Pseudo R-squared & 0.1293 & & & \\
\hline
\end{tabular}

Bootstrapped standard errors employed. Regional-level fixed effects employed

$\dagger p \leq 0.10 ; * p \leq 0.05 ; * * p \leq 0.01 ; * * * p \leq 0.001$

hypothesis that displacement to a shelter is uniquely associated with vulnerability. Dwelling ownership is associated with a $3.41 \%$ increase in probability of experiencing displacement to other types of interim housing (ref: renter, predicted probability $=$ $13.92 \%)$. Nonagricultural livelihoods are associated with a $4.57 \%$ increase in the probability of experiencing displacement to other types of interim housing (ref: agricultural livelihoods, predicted probability $=14.23 \%$ ). And particularly notable, we find female headship is associated with a $11.31 \%$ decrease in the probability of experiencing displacement to other types of interim housing (ref: male headship, predicted probability $=18.35 \%$ ) - a marked contrast from the increased likelihood with female household headedness associated with displacement to a shelter.

\section{Models predicting disease outcomes}

Table 5 presents results of estimations of the effect of displacement to shelter and other types of interim housing on health outcomes. Model 1, predicting diarrheal disease, finds no statistically significant effect of displacement to shelters, or displacement to other types of interim housing. There is an observable and robust effect of time on diarrheal disease. The AME of the time point variable finds the post-disaster time point is associated with a $30.57 \%$ increase in the probability of having diarrheal disease symptoms. We posit that this association is likely related to other effects and experiences associated with the hurricane aside from displacement, given that the sample is 
Table 5 Two-way fixed-effects binomial logistic regression predicting disease symptoms

\begin{tabular}{|c|c|c|c|c|}
\hline & \multicolumn{2}{|c|}{$\begin{array}{l}\text { Model 1; } \\
\text { diarrheal disease }\end{array}$} & \multicolumn{2}{|c|}{$\begin{array}{l}\text { Model 2; } \\
\text { respiratory disease }\end{array}$} \\
\hline & Odds Ratio & $\mathrm{P}>\mathrm{t}$ & Odds Ratio & $\mathrm{P}>\mathrm{t}$ \\
\hline Displacement to shelter & 0.67 & 0.667 & $1.84 * *$ & 0.009 \\
\hline Displacement to other types of interim housing & 0.55 & 0.365 & $0.50 * *$ & 0.001 \\
\hline Year 1999 & $4.00 * *$ & 0.000 & $0.75 * * *$ & 0.000 \\
\hline $\mathrm{N}$ & 3474 & & 3474 & \\
\hline Wald chi-squared & 17.82 & 0.001 & 41.50 & 0.000 \\
\hline
\end{tabular}

comprised of individuals who all resided in heavily affected communities. Model 2, estimating respiratory disease symptoms as predicted by displacement to a shelter, finds statistically significant effects of displacement on the health outcome. Shelter displacement is associated with a $14.78 \%$ increase in the probability of having respiratory disease. And in contrast, model 2 finds displacement to other types of interim housing is associated with a $16.04 \%$ decrease in the probability of having respiratory diseasean unexpected result which suggests that non-shelter locations buffered individuals from certain negative effects of the hurricane.

\section{Limitations}

While the Nicaragua LSMS data are exceptional in providing detailed individual and household information preceding and following a major disaster event, the data are limited in certain respects. A first limitation relates to the time specification of our health outcome variables. Respiratory and diarrheal disease are measured at a single post-disaster point in time, over the last month from the data collection time point. The timing of the post-disaster survey, 7 and 8 months after the hurricane, does not allow for insight into health conditions that existed in initial months, but did not persist longer. This data limitation might be linked to the null findings linking displacement with diarrheal disease, as such illness may be more acute and resolved by the time the question about diarrhea "in the past month" was asked. A more detailed health history, with diagnosis provided by health professionals, would provide clearer insights into the causal relationship between displacement and incidence of chronic disease across differentially affected populations.

Relatedly, with the post-disaster survey carried out 7 and 8 months after the event and with almost all displacements resolved after 4 months had passed (USAID 1999), we have limited information on the timing of movements/displacements over this 8month period. An ideal study would be able to document the timing of movements and place the timing of movements relative to the timing of disease contraction. Further, small sample size and a limited number of respondents experiencing forms of displacement other than a shelter compelled us to combine all other displacements into a single category representing all other types of interim housing. We acknowledge that this is a 
coarse measure, which risks conflating movements with different associated characteristics.

As several disaster and health scholars note, post-disaster samples may be biased due to selective population losses (Fussell and Lowe 2014; Galea, Waxwell, \& Norris, 2008; Norris, 2006). While pre- and post-event measures provide some leverage, we lack adequate information on the extent to which households were differentially located by INEC for follow-up in the post-disaster collection wave and how potential selection may have contributed to biased results. Another potential issue is possible residual confounding, where the most heavily impacted areas would be associated with both generally worse health outcomes and heightened likelihood of experiencing displacement. However, the study design, which includes in the post-disaster wave only households who resided in areas that became heavily impacted, implies displacement to be a differentiated experience among those from heavily impacted areas. We do acknowledge that not all "heavily affected" areas are equally affected; therefore, we cannot entirely dismiss the residual confounding issue.

\section{Discussion}

Other studies have documented the marked uptick of rates of infectious disease in Nicaragua following Hurricane Mitch. This study provides insight into this aggregate trend, finding specific individual experiences linked to contracting communicable diseases following Hurricane Mitch. Our results suggest that net of socioeconomic characteristics, displacement to a shelter is associated with heightened risk of respiratory infection, while displacement to other sites (i.e., the home of family/ friends, an improvised dwelling, another department, another municipality or another country) exhibits no such association. This finding is consistent with a literature finding respiratory diseases to thrive under the unsanitary and crowded conditions that displacement shelters often feature. The current analyses find no statistically significant association between displacement - of any type — and risk of diarrheal disease. Yet, we find the post-disaster time point has a robust, positive association with the diarrheal disease outcome, suggesting that there was an effect of the hurricane on diarrheal disease across all in the "heavily affected," postdisaster sample. These results are consistent with research that finds diarrheal disease outbreaks in the context of disasters result mainly from water contamination, a frequent effect of disasters that occurs not only within the confines of shelters but also across entire community water systems (Watson et al. 2007).

Our study of the case of Nicaragua and Hurricane Mitch finds that all forms of displacement are associated with low socio-economic position. These findings suggest that the poor were vulnerable to displacement from a home, likely due to living in marginal dwellings and in more hazardous locales featuring shoddy infrastructure. However, other characteristics associated with social-economic disadvantage are uniquely predictive of displacement to a shelter in particular. Low levels of education, female household headship, and being a home renter are associated with heightened risk of displacement to a shelter, while homeowners, male-headed households, and larger families featured greater likelihood of 
becoming displaced to other types of interim housing-locations that did not feature heightened risk of contracting respiratory disease, but rather exerted protection against respiratory disease.

In analyzing the displacement-health linkage, our study reveals how communitylevel features and distal, individual-level characteristics interact to create disaster vulnerability. In Nicaragua, the state failed to carry out a comprehensive response and recovery plan, limiting its efforts to rebuilding major public infrastructure (Delaney and Shrader 1999). In the vacuum of state leadership on shelter procurement and housing reconstruction, national and international NGOs led an uneven, ad hoc effort (Cupples 2004; Cupples 2007). Schools became emergency shelters, often run by teachers (ECLAC 1999). Sanitation was a problem in these shelters, as was lack of access to water, food, and other essential supplies. As months passed, some persons were able to relocate to temporary shelters better suited for housing persons for extended periods. Others, however, continued to remain housed in inadequate camps where dwellings consisted of plastic tents and where population waste was disposed to overburdened communal latrines (Christoplos et al. 2010; Gerulis-Darcy 2008). These societal-level failures to fulfill essential response and recovery functions had negative impacts on population health that were differentially borne by socially disadvantaged population groups.

Our results that find female-headed households experienced heightened risk of being displaced to shelters are similar to what has been observed in numerous other studies of displacement in the context of disaster events (e.g., Gray et al. 2014; Mallick and Vogt 2014; Twigg 2015) and are relevant to a burgeoning literature on gender, vulnerability, and disaster processes (e.g., Cupples 2007; Cutter 2017; Twigg and Bhatt 1998). Susan Cutter, seminal scholar of disaster vulnerability, notes insufficient attendance to gender in disaster analyses has rendered women and children "undocumented victims" and "forgotten casualties" of global environmental change (Cutter 2017:117). This study illustrates the linkage between femaleheaded households, comprising approximately $27 \%$ of Nicaraguan households (ECLAC 2004), and the experience of displacement in the Hurricane Mitch case - an experience implicated in negative health outcomes. Our policy recommendation reiterates the prescription put forth by others (Cupples 2007; Delaney and Shrader 1999) that policy makers and disaster managers should acknowledge displacement as a process connected to broader social inequalities in gender and the family and ensure that women are incorporated into response, recovery, and reconstruction planning. Ideally, this occurs in the context of a state-led recovery and reconstruction plan that incorporates the community, along with other major actors.

The finding that engagement with community organizations is associated with increased odds of displacement to a shelter was unexpected and contrary to our hypothesis that social connections provide alternatives to having to resort to a displacement shelter. An alternative explanation is that displacement shelters were selective, discriminating places, access to which was facilitated by social connections. However, all other findings - associated low levels of consumption, lack of dwelling ownership, female household headedness - suggest otherwise. An alternative explanation is that those of lower socioeconomic status participate in community organizations as a recourse to living in communities that lack effective social services and a social safety net. 


\section{Conclusion}

In his widely cited analysis of social determinants of global health disparities, Marmot (2005:1099) notes, "A catastrophe on the scale of the Indian Ocean tsunami rightly focuses attention on the susceptibility of poor and vulnerable populations to natural disasters. It is no less important to keep on the agenda the more enduring problem of inequalities in health among countries." We concur with this statement but emphasize that it is also of critical importance to focus upon the intersection of enduring material disparities and the susceptibility of the world's poor to natural disasters. It is ever more critical to grasp the uneven risks of death and disease in an era of unprecedented climate extremes and climate-induced disasters (IPCC 2013). Recent work has begun to find prolonged effects of natural disaster events on health, particularly in developing regions in which recovery may not be fully attained for extended periods of time. From Louisiana in the cases of Hurricanes Katrina and Rita (Hori and Schafer 2010), South Asia following the tsunami of 2004 (Rodriguez et al. 2006), and Haiti following the 2010 earthquake (Ferris and Ferro-Ribeiro 2012), evidence has been found for persistent ill health effects of disasters. Scholars working in these settings are illuminating the circumstances that link disasters and health, such as persistently poor access to health care, and as we demonstrate, the risk of emergency shelter displacement. As a result, a critical knowledge base is taking shape from which to formulate policy to address health disparities and disease risks in disaster-prone communities.

Threats related to disaster vulnerability may have aggregate implications for global health inequalities and the global burden of disease. In his far-reaching analysis, McMichael (2003) observes that consideration of global climatic-environmental hazards to human population health must be central to debates on the sustainability transition. Given that climate-induced disaster events show no sign of abating, and that morbidity and mortality risks are uniquely elevated in the course of disaster events and associated displacement, further understanding of the nature of risk and resilience for ill health outcomes in post-disaster contexts is urgently needed to promote effective prevention and preparedness measures. We conclude by calling for future research of disaster-impacted populations, examining for longer-term potential threats to health, such as loss of food supply, and lack of health access, as climate change may make these experiences, along with displacement, more regular features of life in the Global South.

Acknowledgements We wish to thank Dr. Jinchun Yuan, Professor at Elizabeth City State University, for assisting with producing the map included in Fig. 1.

\section{References}

Adams, V., Kaufman, S. R., Van Hattum, T., \& Moody, S. (2011). Aging disaster: mortality, vulnerability, and long-term recovery among Katrina survivors. Medical Anthropology, 30(3), 247-270.

Baez, J. E., \& Santos, I. V. (2007). Children's vulnerability to weather shocks: a natural disaster as a natural experiment. New York: Social Science Research Network.

Bellos, A., Mulholland, K., O'Brien, K. L., Qazi, S. A., Gayer, M., \& Checchi, F. (2010). The burden of acute respiratory infections in crisis-affected populations: a systematic review. Conflict and Health, 4(1), 3. 
Blaikie, P., Cannon, T., Davis, I., \& Wisner, B. (2014). At risk: natural hazards, people's vulnerability and disasters. New York: Routledge.

Bolin, R. C. \& Stanford, L. (1990). Shelter and housing issues in Santa Cruz County. The Loma Prieta Earthquake: Studies of Short-Term Impacts. Program on environment and behavior monograph no. 50. Institute of Behavioral Science, University of Colorado.

Brodie, M., Weltzien, E., Altman, D., Blendon, R. J., \& Benson, J. M. (2006). Experiences of Hurricane Katrina evacuees in Houston shelters: Implications for future planning. American Journal of Public Health, 96(8), 1402-1408.

Cameron, A. C., \& Trivedi, P. K. (2010). Microeconometrics using Stata (Vol. 2). College Station: Stata Press.

Cameron, A. C., Gelbach, J. B., \& Miller, D. L. (2008). Bootstrap-based improvements for inference with clustered errors. The Review of Economics and Statistics, 90(3), 414-427.

Campanella, N. (1999). Infectious diseases and natural disasters: the effects of Hurricane Mitch over Villanueva municipal area, Nicaragua. Public Health Reviews, 27(4), 311-319.

Campbell-Lendrum, D., \& Woodruff, R. (2006). Comparative risk assessment of the burden of disease from climate change. Environmental Health Perspectives, 114(12), 1935.

Carvajal, L., \& Pereira, M. I. (2009). Climate shocks and human mobility: evidence from Nicaragua. SSRN. Available at: https://ssrn.com/abstract=1599667 or https://doi.org/10.2139/ssrn.1599667. Accessed 20 Apr 2019.

Chaisemartin, C. D., \& Haultfoeuille X. (2018). Two-way fixed effects estimators with heterogenous treatment effects. Ithaca: Cornell University. arXiv:1803.08807.

Christoplos, I., Rodríguez, T., Schipper, E. L. F., Narvaez, E. A., Mejia, B., Maria, K., Buitrago, R., Gómez, L., \& Pérez, F. J. (2010). Learning from recovery after hurricane Mitch. Disasters, 34(s2), s202-s219.

Coleman, J. S. (1988). Social capital in the creation of human capital. The American Journal of Sociology, 94 , S95-S120.

Cupples, J. (2004). Rural development in El Hatillo, Nicaragua: Gender, neoliberalism and environmental risk. Singapore Journal of Tropical Geography, 25(3), 343-357.

Cupples, J. (2007). Gender and hurricane Mitch: reconstructing subjectivities after disaster. Disasters, 31(2), $155-175$.

Cutter, S. L. (2017). The forgotten casualties redux: women, children, and disaster risk. Global Environmental Change, 42, 117-121.

Cutter, S. L., \& Emrich, C. T. (2016). Moral hazard, social catastrophe: The changing face of vulnerability along the hurricane coasts. The ANNALS of the American Academy of Political and Social Science, 604(1), 102-112.

Cutter, S. L., Boruff, B. J., \& Shirley, W. L. (2003). Social vulnerability to environmental hazards. Social Science Quarterly, 84(2), 242-261.

Davis, J. (2017). Fertility after natural disaster: Hurricane Mitch in Nicaragua. Population and Environment, 38(4), 448-464.

Delaney, P. L., \& Shrader, E. (2000). Gender and post-disaster reconstruction: The case of Hurricane Mitch in Honduras and Nicaragua. Decision review draft. Washington, DC: LCSPG/LAC Gender Team, The World Bank.

Economic Commission for Latin America and the Caribbean (ECLAC). (1999). Nicaragua: assessment of the damage caused by hurricane Mitch 1998: implications for economic and social development and for the environment. Mexico City: ECLAC.

Economic Commission for Latin America (ECLAC). (2004). Panorama social de América Latina. Santiago: ECLAC.

Elliott, J. R., Haney, T. J., \& Sams-Abiodun, P. (2010). Limits to social capital: comparing network assistance in two New Orleans neighborhoods devastated by hurricane Katrina. The Sociological Quarterly, 51(4), 624-648.

Ezzati, M., Lopez, A. D., Rodgers, A., Vander Hoorn, S., \& Murray, C. J. L. (2002). Selected major risk factors and global and regional burden of disease. Lancet, 360(9343), 1347-1360.

Ferris, E., \& Ferro-Ribeiro, S. (2012). Protecting people in cities: the disturbing case of Haiti. Disasters, 36, S43-S63.

Few, R. (2007). Health and climatic hazards: framing social research on vulnerability, response and adaptation. Global Environmental Change, 17(2), 281-295.

Few, R., \& Tran, P. G. (2010). Climatic hazards, health risk and response in Vietnam: case studies on social dimensions of vulnerability. Global Environmental Change, 20(3), 529-538.

Finch, C., Emrich, C. T., \& Cutter, S. L. (2010). Disaster disparities and differential recovery in New Orleans. Population and Environment, 31(4), 179-202. 
Fothergill, A., \& Peek, L. A. (2004). Poverty and disasters in the United States: a review of recent sociological findings. Natural Hazards, 32(1), 89-110.

Fussell, E., \& Lowe, S. R. (2014). The impact of housing displacement on the mental health of low-income parents after hurricane Katrina. Social Science \& Medicine, 113, 137-144.

Galea, S., Maxwell, A. R., \& Norris, F. (2008). Sampling and design challenges in studying the mental health consequences of disasters. International Journal of Methods in Psychiatric Research, 17(S2), S21-S28.

Gee, G. C., \& Payne-Sturges, D. C. (2004). Environmental health disparities: a framework integrating psychosocial and environmental concepts. Environmental Health Perspectives, 112(17), 1645.

Gerulis-Darcy, M.L. (2008). Vulnerability and the social-production of disaster: Hurricane Mitch in Posoltega, Nicaragua. Ph.D. dissertation. Department of Sociology and Anthropology, Northeastern University, Boston, Massachusetts.

Ginexi, E. M., Weihs, K., Simmens, S. J., \& Hoyt, D. R. (2000). Natural disaster and depression: a prospective investigation of reactions to the 1993 midwest floods. American Journal of Community Psychology, 28(4), 495-518.

Goenjian, A. K., Roussos, A., Steinberg, A. M., Sotiropoulou, C., Walling, D., Kakaki, M., \& Karagianni, S. (2011). Longitudinal study of PTSD, depression, and quality of life among adolescents after the Parnitha earthquake. Journal of Affective Disorders, 133(3), 509-515.

Gordon-Larsen, P., Nelson, M. C., Page, P., \& Popkin, B. M. (2006). Inequality in the built environment underlies key health disparities in physical activity and obesity. Pediatrics, 117(2), 417-424.

Gray, C., Frankenberg, E., Gillespie, T., Sumantri, C., \& Thomas, D. (2014). Studying displacement after a disaster using large-scale survey methods: Sumatra after the 2004 tsunami. Annals of the Association of American Geographers, 104(3), 594-612.

Greenough, G., Lappi, M. D., Hsu, E. B., Fink, S., Hsieh, Y., Vu, A., Heaton, C., \& Kirsch, T. D. (2008). Burden of disease and health status among hurricane Katrina-displaced persons in shelters: a populationbased cluster sample. Annals of Emergency Medicine, 51(4), 426-432.

Hori, M., \& Schafer, M. J. (2010). Social costs of displacement in Louisiana after hurricanes Katrina and Rita. Population and Environment, 31, 64-86.

Hugo, D. (1996). Environmental concerns and international migration. International Migration Review, 30, 247-277.

Imai, K. \& Song, K. (2012). On the use of linear fixed effects regression models for causal inference. Technical Report. Princeton University. Available at http://imai.princeton.edu/research/FEmatch.html. Accessed 20 Apr 2019.

Intergovernmental Panel on Climate Change. (2013). Climate change 2013: the physical science basis. Cambridge: Cambridge University Press.

Jakobsen, K. T. (2012). In the eye of the storm - the welfare impacts of a hurricane. World Development, 40, 2578-2589.

Kaniasty, K., \& Norris, F. H. (2000). Help-seeking comfort and receiving social support: the role of ethnicity and context of need. American Journal of Community Psychology, 28(4), 545-581.

Klinenberg, E. (1999). Denaturalizing disaster: a social autopsy of the 1995 Chicago heat wave. Theory and Society, 28, 239-295.

Leaning, J., \& Guha-Sapir, D. (2013). Natural disasters, armed conflict, and public health. New England Journal of Medicine, 369, 1836-1842.

Levine, J. N. (2007). Population displacement and housing dilemmas due to catastrophic disasters. Journal of Planning Literature, 22(1), 3-15.

Lindsay, J. R. (2003). The determinants of disaster vulnerability: achieving sustainable mitigation through population health. Natural Hazards, 28(2-3), 291-304.

Loebach, P. (2016). Household migration as a livelihood adaptation in response to a natural disaster: Nicaragua and hurricane Mitch. Population and Environment, 38(2), 185-206.

Loebach, P. (2019). Livelihoods, precarity and disaster vulnerability: Nicaragua and hurricane Mitch. Disasters, Forthcoming.

Lopez, A. D., Mathers, C. D., Ezzati, M., Jamison, D. T., \& Murray, C. J. (2006). Global and regional burden of disease and risk factors, 2001: systematic analysis of population health data. Lancet, 367(9524), 17471757.

Mallick, B., \& Vogt, J. (2014). Population displacement after cyclone and its consequences: empirical evidence from coastal Bangladesh. Natural Hazards, 73(2), 191-212.

Marmot, M. (2005). Social determinants of health inequalities. Lancet, 365(9464), 1099-1104.

McHugh, L. (1999). Central America: reconstruction after hurricane Mitch. Washington, D.C.: CRS Report for Congress. Congressional Research Service. The Library of Congress. 
McLeman, R. A., \& Hunter, L. M. (2010). Migration in the context of vulnerability and adaptation to climate change: insights from analogues. Wiley Interdisciplinary Reviews: Climate Change, 1(3), 450-461.

McLeman, R., Schade, J., \& Faist, T. (Eds.). (2016). Environmental migration and social inequality. Dordrecht: Springer.

McMichael, A. J. (2003). Global climate change and health: an old story writ large. Climate change and human health: Risks and responses. Geneva: World Health organization.

McMichael, A. J. (2013). Globalization, climate change, and human health. The New England Journal of Medicine, 368(14), 1335-1343.

McMichael, A. J., Woodruff, R. E., \& Hales, S. (2006). Climate change and human health: present and future risks. Lancet, 367(9513), 859-869.

Morris, S. S., Neidecker-Gonzales, O., Carletto, C., Munguía, M., Medina, J. M., \& Wodon, Q. (2002). Hurricane Mitch and the livelihoods of the rural poor in Honduras. World Development, 30(1), 49-60.

Morrow-Jones, H. A., \& Morrow-Jones, C. R. (1991). Mobility due to natural disaster: theoretical considerations and preliminary analyses. Disasters, 15(2), 126-132.

Myers, C. A., Slack, T., \& Singelman, J. (2008). Social vulnerability and migration in the wake of disaster: the case of hurricanes Katrina and Rita. Population and Environment, 29, 271-291.

National Oceanic and Atmospheric Administration (NOAA). 2009. Mitch: the deadliest Atlantic hurricane since 1780. Retrieved April 30, 2015 (http://www.ncdc.noaa.gov/oa/reports/mitch/mitch.html).

Noji, E. K. (2005). Public health issues in disasters. Critical Care Medicine, 33(1), S29-S33.

Norris, F. H. (Ed.). (2006). Methods for disaster mental health research. New York: Guilford Press.

Paavola, J. (2008). Livelihoods, vulnerability and adaptation to climate change in Morogoro, Tanzania. Environmental Science \& Policy, 11(7), 642-654.

PAHO. (2000). Natural disasters: protecting the public's health. No. 575. Washington DC: Pan American Health Organization.

Patz, J. A., Campbell-Lendrum, D., Holloway, T., \& Foley, J. A. (2005). Impact of regional climate change on human health. Nature, 438(7066), 310-317.

Patz, J. A., Gibbs, H. K., Foley, J. A., Rogers, J. V., \& Smith, K. R. (2007). Climate Change and Global Health: Quantifying a Growing Ethical Crisis. EcoHealth, 4(4), 397-405.

Peacock, W. G., Dash, N., \& Zhang, Y. (2007). Sheltering and housing recovery following disaster. In W. A. Andersson, P. A. Kennedy \& Ressler (Eds.), Handbook of disaster research (pp. 258-274). New York: Springer.

Pelling, M., \& High, C. (2005). Understanding adaptation: what can social capital offer assessments of adaptive capacity? Global Environmental Change, 15(4), 308-319.

Premand, P., \& Vakis, R. S. (2010). Do shocks affect poverty persistence? Evidence using welfare trajectories from Nicaragua. Well-Being and Social Policy, 6, 95-129.

Quarantelli, E. L. (1982). General and particular observations on sheltering and housing in American disasters. Disasters, 6(4), 277-281.

Rodriguez, H., Wachtendorf, T., Kendra, J., \& Trainor, J. (2006). A snapshot of the 2004 Indian Ocean tsunami: Societal impacts and consequences. Disaster Prevention and Management: An International Journal, 15(1), 163-177.

Rofi, A., Doocy, S., \& Robinson, C. (2005). Tsunami mortality and displacement in Aceh Province, Indonesia. Disasters, 30(6), 340-350.

Ross, C. E., \& Mirowsky, J. (2001). Neighborhood disadvantage, disorder, and health. Journal of Health and Social Behavior, 42, 258-276.

Sakisaka, K., Wakai, S., Kuroiwa, C., Flores, L. C., Kai, I., Arago, M. M., \& Hanada, K. (2006). Nutritional status and associated factors in children aged 0-23 months in Granada, Nicaragua. Public Health, 120(5), $400-411$.

Steele, D. (2001). Supplemental information document: Nicaragua living standards measurement study survey, post-Mitch survey 1999. Geneva: World Bank.

Tierney, K. J. (2006). Social inequality, hazards, and disasters. In R. J. Daniels, D. F. Kettl, \& H. Kenreuther (Eds.), On Risk and Disaster: Lessons from Hurricane Katrina (pp. 109-128). Philadelphia: University of Pennsylvania Press.

Toole, M. J. (1997). Communicable diseases and disease control. In E. Noji (Ed.), The public health consequences of disasters (pp. 79-100). New York: Oxford University Press.

Toole, M. J. (2005). Forced migrants: refugees and internally displaced persons. In B. Levy (Ed.), Social Injustice and Public Health (pp. 190-204). Oxford: Oxford University Press.

Twigg, J. (2015). Disaster risk reduction. London: Overseas Development Institute, Humanitarian Policy Group. 
Twigg, J., \& Bhatt, M. R. (1998). Understanding vulnerability: South Asian perspectives. London: Intermediate Technology Publication Limited.

USAID. (1999). After hurricane Mitch: municipal infrastructure reconstruction in Nicaragua. Report No. PDABR-527. United States Government Interagency Task Force.

Uscher-Pines, L. (2009). Health effects of relocation following disaster: a systematic review of the literature. Disasters, 33(1), 1-22.

Van den Berg, M. (2010). Household income strategies and matural disasters: dynamic livelihoods in rural Nicaragua. Ecological Economics, 69, 592-602.

Villacis, C. (2004). Latin American cases. Recovery and Reconstruction Reports. Asian Disaster Reduction Center. Accessed on 11/28/2018 at http://www.adrc.asia/publications/recovery_reports/pdf/Mitch.pdf

Waring, S. C., \& Brown, B. J. (2005). The threat of communicable diseases following natural disasters: a public health response. Disaster Management \& Response, 3(2), 41-47.

Watson, J. T., Michelle, G., \& Connolly, M. (2007). Epidemics after natural disasters. Emerging Infectious Diseases, 13(1), 1-5.

Williams, R. (2012). Using the margins command to estimate and interpret adjusted predictions and marginal effects. The Stata Journal, 12(2), 308-331.

Wolsko, C., \& Marino, E. (2016). Disasters, migrations, and the unintended consequences of urbanization: What's the harm in getting out of harm's way? Population and Environment, 37(4), 411-428.

World Bank. (1998). Bank unveils new support for Hurricane Mitch recovery. World Bank News (December 17, 1998). Accessed at: http://go.worldbank.org/NEJUYQA840 on April 20, 2019.

Publisher's note Springer Nature remains neutral with regard to jurisdictional claims in published maps and institutional affiliations. 